\title{
On the Method of Determining Spring Flow Rates When Changing Their Positive Pressure Head
}

\author{
NG Aloyan* \\ National Agrarian University of Armenia, Russia \\ *Corresponding author: NG Aloyan, National Agrarian University of Armenia, Russia
}

\begin{tabular}{ll}
\hline ARTICLE INFO & ABSTRACT \\
\hline
\end{tabular}

Received: 幽 May 08, 2021

Published: 蔧 May 27, 2021

Citation: NG Aloyan. On the Method of Determining Spring Flow Rates When Changing Their Positive Pressure Head. Biomed J Sci \& Tech Res 36(1)-2021. BJSTR. MS.ID.005802.
The problem of forecasting changes in the flow rates of natural ascending springs, when water is taken from a confined aquifer, is considered. It is accepted with sufficient accuracy that an ascending spring can be regarded as a kind of (self-flowing) well, using the hydrogeological methods developed for it. It is proposed to determine the change in the flow rates of the spring, with the redistribution of the pressure in the aquifer as a result of water intake, using the indicator curve. With a steady filtration movement, a computational method is proposed to construct this curve using data from field studies of the spring.

Keywords: Ascending Spring; Aquifer; Piezometric Head; Flow Rate; Indicator Curve

\section{Introduction}

From the characteristic border areas of the artesian basin of the Ararat valley, as well as from the geological windows of the water-resistant strata, groundwater in the form of natural springs comes to the surface. Depending on the lithological structure, hydrogeological characteristics and the effective pressure, the values of their flow rates range from several $\mathrm{m}^{3} / \mathrm{s}$ to several $\mathrm{l} / \mathrm{s}$.

\section{Materials and Methods}

The large springs of the valley are Metsamor-Aknalich: with a total flow rate of approximately $19 \mathrm{~m}^{3} / \mathrm{s}$, Sarvanlar: $166 \mathrm{l} / \mathrm{s}$, Uchkerpin: 491 l/s, Norzlu: $225 \mathrm{l} / \mathrm{s}$ and Kapuyt Lich: $2.6 \mathrm{~m}^{3} / \mathrm{s}$. The waters of these springs are now almost entirely used for irrigation, water supply and household needs. In addition to these large, in a number of rural areas of the valley there are many small natural springs, the waters of which are the main, in some cases even the only, sources of drinking water for the community. An intensive water intake is carried out from the artesian basin of the valley, especially from its high-pressure horizon, which is mainly associated with the construction of the now widespread fishery ponds. The springs operating on the valley are mainly hydraulically connected to the high-pressure horizon. As a result of the CIP and massive water withdrawal from this horizon, the flow rates of the springs are greatly reduced and often completely dry up. To avoid this, it is necessary to streamline and systematize the water intake. An ordered water intake presupposes to first find out the expected regularity of the redistribution of the pressure in the aquifer, in particular, the amount of pressure drops near the spring and, in accordance with this, predict the amount of the drop in the flow rate of the spring. If necessary, preventive measures can be taken, in particular, reducing the volume of water intake, increasing the distance of water intake structures from the spring, shortening the duration of water intake, etc.

But there is still no reliable calculation method that will allow the above to be carried out. Below is a calculation method, with the help of which, with some approximation, it is possible to determine the drop in the flow rate of the spring, with a decrease in the positive piezometric head near it. This method assumes that, according to the hydrogeological and hydrodynamic analogy, ascending springs with sufficient accuracy can be considered as a self-flowing (gushing) well, the flow rate of which also largely depends on the hydraulic resistance arising inside it. Let us consider the case of a steady filtration movement, which is typical for most natural springs. For the flow rate of gushing (self-flowing) wells, in a steady state of motion, in $[1,2]$, a calculation formula was obtained, which 
can be written in the following form relative to the spring:

$$
\begin{aligned}
& Q=\frac{\sqrt{F_{o}^{2}+16 \pi^{2} T^{2} 2 \eta_{p} H_{p}}-F_{o}}{4 \pi T \eta_{p}} \\
& T=k m F_{o}=\ln \frac{R}{r_{p}}
\end{aligned}
$$

where

$\mathrm{T}$ is the conductivity of the aquifer, $\mathrm{k}$ is the coefficient of its filtration, $m$ is its power, $H_{p}$ is the positive piezometric pressure at the spring, $r_{p}$ is the reduced radius of the spring, $n_{p}$ is the total hydraulic resistance of the spring, $\mathrm{R}$ is the radius of the source (influence). As a result of water intake, the pressure is redistributed in the aquifer, and under certain conditions, a decrease in $H_{p}$ is possible. The magnitude of this decrease is determined by the corresponding hydrogeological calculation methods, which, depending on the water intake method, are given: in [3,4] for wells operating with deep pumps, and in [5] for gushing wells. The value of the flow rate of the spring, corresponding to this changed value of $\mathrm{H}_{\mathrm{p}}$, can be determined if the indicator curve of the spring is plotted in advance. The construction of this curve can be carried out using formula [1], if the values of the parameters included in it are previously determined.

The hydrogeological characteristics of the aquifer, as a rule, are determined as a result of field research work on the design of water supply wells Moreover, if the spring is located at the edge of the aquifer, then with sufficient accuracy it can be assumed that $\mathrm{R}$ remains constant, and its value will also be determined using data from field research observations. The values of the calculated characteristics of the spring $\eta_{p}$ and $r_{p}$ are determined by the data of specially carried out field measurements using the formula (1) of the flow rate of the spring. From this formula for $\eta_{p}$ and $F_{o}$, respectively, we can write.

$$
\begin{aligned}
& n_{q}=\frac{H_{P}}{Q^{2}}-\frac{F_{0}}{2 \pi T Q} \\
& F_{o}=2 \pi T Q\left(\frac{H_{P}}{Q^{2}}-n_{p}\right)
\end{aligned}
$$

To determine these unknowns, it is necessary to conduct observations of the flow rates and positive pressures in the spring at two different points in time. It is advisable to do this in spring and late summer, when the amplitude of natural fluctuations in groundwater levels will be greatest. It is clear that the filtration motion in these two moments must be steady-state or quasistationary. If equation (1) is written for these two observations, then after some simple changes for $\eta_{p}$ we get the following dependence:

$$
n_{p}=\frac{H_{p 1} Q_{2}-H_{p 2} Q_{1}}{Q_{1} Q_{2}\left(Q_{1}-Q_{2}\right)}
$$

Having the value of $\eta_{p}$ and taking into account the value $F_{o}=\ln \frac{R}{r_{p}}$, from equation (3) for $\mathrm{r}_{\mathrm{p}}$ we can write:

$$
r_{p}=\exp \left[\ln \mathrm{R}_{\mathrm{e} p}-2 \pi T Q_{1} \frac{H_{P 1}}{Q_{1}^{2}}-\frac{H_{p 1} Q_{2}-H_{p 2} Q_{1}}{Q_{1} Q_{2}\left(Q_{1}-Q_{2}\right)}\right]
$$

If a natural spring comes to the surface through a geological window, then it is possible that in this case the radius of its feeding at different points of observation will be different. In this case, at a certain distance from the spring, it is necessary to lay an observation well and measure the piezometric pressure in it. Based on these measurements, for each case, the power radius $(\mathrm{R})$ is proposed to be determined according to the following relationship:

$$
\begin{aligned}
R & =\exp \left(\frac{\pi T S_{i}}{Q_{i}}+\ell n r\right), \\
S_{i} & =H_{e}-H_{i}
\end{aligned}
$$

where

$r$ is the distance of the observation well from the spring, $\mathrm{S}_{\mathrm{i}}$ is the pressure drop in the observation well during the $\mathrm{i}$-th measurement, $\mathrm{H}_{\mathrm{i}}$ is the piezometric pressure in the observation well, $\mathrm{i}$ is the number of measurements ( $\mathrm{i}=1.2$ ), $\mathrm{H}_{\mathrm{e}}$ is the piezometric pressure in the aquifer recharge zone horizon.

Having determined the value of $\mathrm{R}$ according to formula [5], it is possible to calculate the value of $r_{p}$ from the data of two observations, and the equality or proximity of their values will indicate the accuracy of the general calculations. At the same time, when calculating $r_{p}$ according to the data of the $2^{\text {nd }}$ measurement, it is necessary to include the values of $H_{p}$ and $Q$ of the same measurement in formula [5], according to expression [3]. For the purpose of a clear demonstration of the above, the figure below shows the constructed indicator curve of a spring located in the village of Sis (Armavir region) on the edge of the artesian basin of the Ararat valley. In the calculations, we used archival materials of field studies carried out by the Geological Department [6]. Based on these materials, the obtained values of the main characteristics are as follows: $T=1200 \mathrm{~m}^{2} /$ day, $R=2000 \mathrm{~m}, \mathrm{r}_{\mathrm{p}}=0.075 \mathrm{~m}, \eta_{\mathrm{p}}=9$. 10-8 days ${ }^{2} / \mathrm{m}^{5}$. It should be noted that the indicator curve makes it possible to calculate a new value of $Q$ if, due to the tersmination of water intake at the spring, an increase in the piezometric pressure occurs. It should be noted that the indicator curve makes it possible to calculate a new value of $Q$ if, due to the termination of water intake at the spring, an increase in the piezometric pressure occurs (Figure 1). 


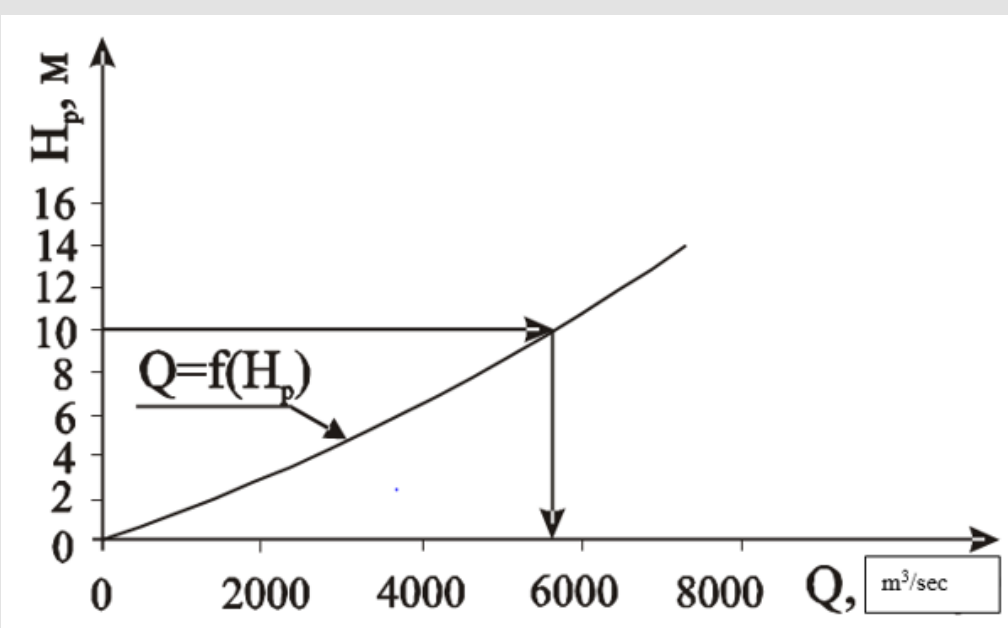

Figure 1: Spring indicator curve.

\section{Conclusion}

a) When drawing up projects of water intake from an artesian pressurized aquifer horizon, it is necessary to predict due to this drop in production rates of closely located natural springs.

b) Natural ascending springs can be viewed with sufficient accuracy as a kind of gushing (self-flowing) well and to them to apply the hydrogeological calculation methods developed for these wells.

c) Change in flow rates when the piezometric positive head can be determined by plotting an indicator curve using formulas [4-6].

\section{References}

1. Melikyan NL (2005) Water intake by flowing wells in a stationary filtration mode, considering downhole hydraulics. News of Agrarian Science 4(3): 165-169.

\section{ISSN: 2574-1241}

DOI: $10.26717 /$ BJSTR.2021.36.005802

NG Aloyan. Biomed J Sci \& Tech Res

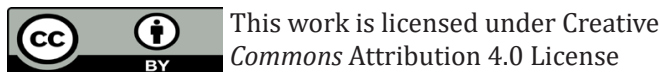

Submission Link: https://biomedres.us/submit-manuscript.php
2. Fetter CW (1994) Applied Hydrology ( $3^{\text {rd }}$ Edn.)., Prentice-Hall, Inc New Jersey, pp. 691.

3. Bochever FM (1965) Fundamentals of hydrogeological calculations. Moscow Nedra, pp. 306

4. Kruseman GP, Ridder NA (1994) Analysis and evaluation of pumping test data ( $\left.2^{\text {nd }} E d n.\right) .$, (completely revised). Netherland, pp. 377.

5. Melikyan NL (2006) Methods for effective management and use of operational reserves of artesian basin waters. Doctoral dissertation Yerevan, pp. 350.

6. (1983) Reassessment of the operational reserves of groundwater in the Ararat artesian basin of the Armenian SSR as of 09.83. Report of the State University.

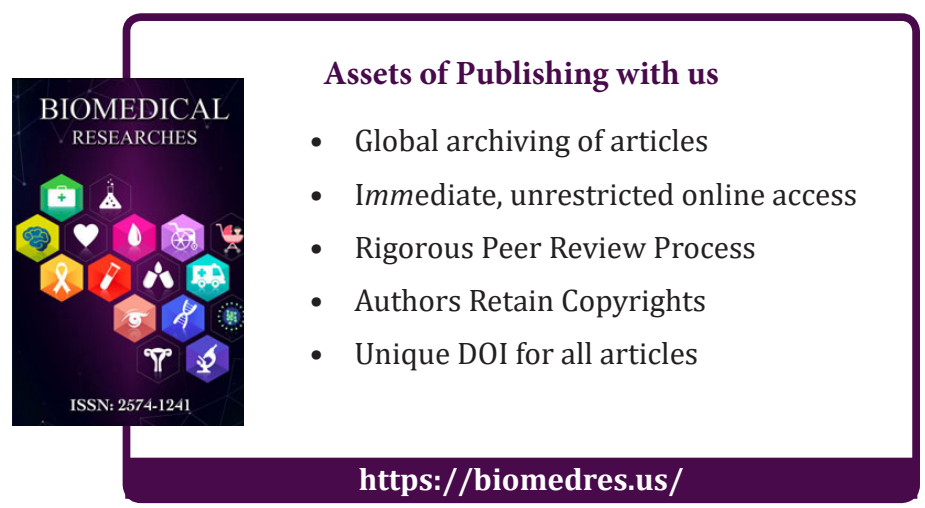

